\title{
Surto de abscesso mandibular por Pseudomonas aeruginosa em ovinos ${ }^{1}$
}

\author{
Rogério Martins Amorim², Hugo Shisei Toma ${ }^{2 *}$, Luiz Carlos Vulcano ${ }^{3}$, Márcio \\ Garcia Ribeiro ${ }^{4}$, Simone Fernandes ${ }^{5}$, Alexandre Secorun Borges ${ }^{2}$, Simone Biagio \\ Chiacchio $^{2}$ e Roberto Calderon Gonçalves ${ }^{2}$
}

\begin{abstract}
Amorim R.M., Toma H.S., Vulcano L.C., Ribeiro M.G., Fernandes S., Borges A.S., Chiacchio S.B. \& Gonçalves R.C. 2011. [Outbreak of mandibular abscess by Pseudomonas aeruginosa in sheep.] Surto de abscesso mandibular por Pseudomonas aeruginosa em ovinos. Pesquisa Veterinária Brasileira 31(9):747-750. Setor de Clínica de Grandes Animais, Departamento de Clínica Veterinária, Faculdade de Medicina Veterinária e Zootecnia, Unesp-Botucatu, Distrito de Rubião Júnior s/n, Botucatu, SP 18618-000, Brazil. E-mail: hugost@ig.com.br

We describe an outbreak of mandibular abscess in Bergamácia sheep from the municipality of Botucatu, São Paulo, Brazil. In a herd of 120 sheep, 35 showed an increase of the mandibular volume with presence of a single nodule of stony consistency and different sizes, often fistulated but with no signs of inflammation in the surrounding soft tissues. The sheep were raised on a Panicum maximum cv. Tanzania pasture, with water and mineral salt ad libitum, and were treated orally against parasites with drenching pistols. Material for microbiological diagnosis and antibiogram was collected from the nodules of five affected sheep, through puncture and aspiration. From 35 affected sheep, 19 were submitted to radiographic examination, one was submitted to computer tomography and another to bone biopsy of the submandibular region. The only sheep that died was in a state of cachexia, probably due to the location of the volume increase which affected the molar hindering apprehension and appropriate chewing. Necropsy revealed areas of caseous necrosis in the jaw, from where Pseudomonas aeruginosa was isolated. The sheep were treated with intramuscular application of $10 \%$ sodium iodide and the antobiotgic enrofloxacin, but with little efficacy. Based on the clinical data from medical records, the location of lesions in the jaw bone, the result of microbiological culture, radiographic and computer tomography, the diagnosis of mandibular abscesses due to Pseudomonas aeruginosa infection was made.
\end{abstract}

INDEX TERMS: Mandibular abscess, Pseudomonas aeruginosa, drenching guns, sheep.

RESUMO.- Descreve-se um surto de abscesso mandibular em ovelhas da raça Bergamácia no município de Botucatu, estado de São Paulo. Do rebanho de 120 animais, 35 apresentaram aumento de volume mandibular com a presença de nódulos únicos, de consistência pétrea, de diferentes tamanhos,

\footnotetext{
${ }^{1}$ Recebido em 16 de abril de 2011.

Aceito para publicação em 21 de junho de 2011.

2 Departamento de Clínica Veterinária, Faculdade de Medicina Veterinária e Zootecnia (FMVZ), Universidade Estadual Paulista (Unesp), Campus de Botucatu, Distrito de Rubião Júnior s/n, Botucatu, SP 18618-000, Brasil. *Autor para correspondência: hugost@ig.com.br

${ }^{3}$ Departamento de Reprodução Animal e Radiologia Veterinária, FMVZ, Unesp-Botucatu, Botucatu, SP.

${ }^{4}$ Departamento de Higiene Veterinária e Saúde Pública, FMVZ, UnespBotucatu, Botucatu, SP.

${ }^{5}$ Departamento de Produção Animal, FMVZ, Unesp-Botucatu, Fazenda Experimental Lageado, Botucatu, SP 18618-000.
}

fistulados ou não e sem indicativos de inflamação dos tecidos moles adjacentes. Os animais eram criados em pasto de $\mathrm{Pa}$ nicum maximum cv. Tanzânia com água e sal mineral $a d$ libitum e everminados, via oral, com pistolas dosificadoras. 0 material para diagnóstico microbiológico e antibiograma foi coletado de cinco animais acometidos, por punção e aspiração dos nódulos. Dos 35 animais acometidos, 19 foram submetidos ao exame radiográfico, um ao exame tomográfico e outro à biópsia óssea da região submandibular. 0 único ovino que morreu, encontrava-se em estado de caquexia provavelmente devido à localização do aumento de volume que afetou a implantação dos dentes molares daquela região impedindo a apreensão e mastigação adequadas levando a perda da condição corporal e morte. Ao exame necroscópico, observaram-se áreas de necrose caseosa na mandíbula direita de onde isolou-se Pseudomonas aeruginosa. 0 tratamento utilizado foi baseado na aplicação de iodeto de sódio a $10 \%$ por 
via intramuscular e antibioticoterapia segundo antibiograma com enrofloxacina por via intramuscular, porém com pouca eficácia. Diante do quadro clínico, dos dados de anamnese, da localização das lesões no tecido ósseo mandibular, do resultado do cultivo microbiológico, das alterações radiográficas e tomográficas foi feito o diagnóstico de abscesso mandibular causado por Pseudomonas aeruginosa.

TERMOS DE INDEXAÇÃO: Abscesso mandibular, Pseudomonas aeruginosa, pistola dosificadoras, ovinos.

\section{INTRODUÇÃO}

Lesões traumáticas na cavidade oral de ruminantes podem trazer sérias consequências, pois agentes bacterianos oportunistas podem aproveitar essa porta de entrada e migrarem para outros tecidos e sistemas causando alterações inflamatórias graves que podem levar a quadros de infecção secundária. Dentre estes agentes destacam-se Actinomyces bovis e Actinobacillus ligneriesii e outras bactérias incluindo Listeria monocytogenes, Nocardia spp., Staphylococcus aureus, Streptococcus spp., Pseudomonas aeruginosa e Arcanobacterium pyogenes (Radostits et al. 2002, Benito-Peña et al. 2010).

Em ovinos, uma das principais formas de tratamento antihelmíntico consiste na aplicação de drogas, via oral, utilizando as denominadas pistolas dosificadoras. Quando essa técnica não é realizada com os devidos cuidados, lesões traumáticas penetrantes na boca, faringe, laringe e tecidos circunvizinhos podem ocorrer (López 1998, Sant'Ana et al. 2007).

Este trabalho tem por objetivo descrever a ocorrência de surto de abscessos ósseos na região mandibular de ovinos criados no município de Botucatu, São Paulo.

\section{MATERIAL E MÉTODOS}

Foram atendidas 35 ovelhas, adultas, da raça Bergamácia, pertencentes a um rebanho de 120 ovinos, com queixa de aumento de volume mandibular. Nesta região, observou-se a presença de nódulos únicos, de consistência pétrea, de diferentes tamanhos, fistulados ou não e sem indicativos de inflamação dos tecidos moles adjacentes. Os animais eram criados na região de Botucatu/ SP, em pasto de Panicum maximum cv. Tanzânia com água e sal mineral ad libitum e everminados, via oral, com pistolas dosificadoras, quando apresentavam OPG acima de 800. Os ovinos foram submetidos ao exame físico de acordo com Feitosa (2008). O material para diagnóstico microbiológico e antibiograma foi coletado de cinco ovelhas acometidas, por punção e aspiração do conteúdo de nódulos não fistulados, com agulha 40x16. 0 conteúdo obtido pela punção foi semeado em ágar sangue e McConkey e mantido em estufa a $37^{\circ} \mathrm{C}$. Das 35 ovelhas acometidas, 19 foram submetidos ao exame radiográfico da região submandibular e uma foi submetida ao exame tomográfico do crânio e biopsia óssea. As imagens realizadas pelo tomógrafo helicoidal (Shimadzu, SCT-7800TC) foram obtidas com a técnica de $120 \mathrm{kV}, 140 \mathrm{~mA}$, espessura de corte de $1 \mathrm{~mm}$, incremento de $1 \mathrm{~mm}$, tempo de rotação do tubo de raio-x de $1 \mathrm{~s}$ e velocidade da mesa de $1 \mathrm{~mm} / \mathrm{s}$. As imagens foram visualizadas pelo software de visualização DICOM - E-film versão 2.1 .2 \& 3.0.0 da empresa Merge. A reconstrução tridimensional das imagens foi realizada com o software DICOM - Voxar 3D versão 6.3 da empresa Barco. Um dos animais veio a óbito por caquexia, e foi submetido ao exame necroscópico. Os fragmentos ósseos foram fixados em formalina, e em seguida descalcificados. As lâminas histológicas foram coradas com hematoxilina-eosina.

\section{RESULTADOS E DISCUSSÃO}

Ao exame clínico, todos os animais, com exceção do animal que morreu, apresentavam parâmetros fisiológicos dentro da normalidade para a espécie, apresentando apenas aumento de volume único, de consistência pétrea, fixo, na região do ramo inferior da mandíbula. 0 único ovino que veio a óbito encontrava-se em estado de caquexia provavelmente devido à localização do abscesso que afetou a implantação dos dentes molares daquela região impedindo a apreensão e mastigação adequadas que o levou a perda da condição corporal e morte.

Ao exame necroscópico, observaram-se áreas circulares e focais de necrose caseosa na mandíbula direita, na altura do terceiro dente molar, com aproximadamente sete centímetros de diâmetro sem alterações significativas em outros ór-

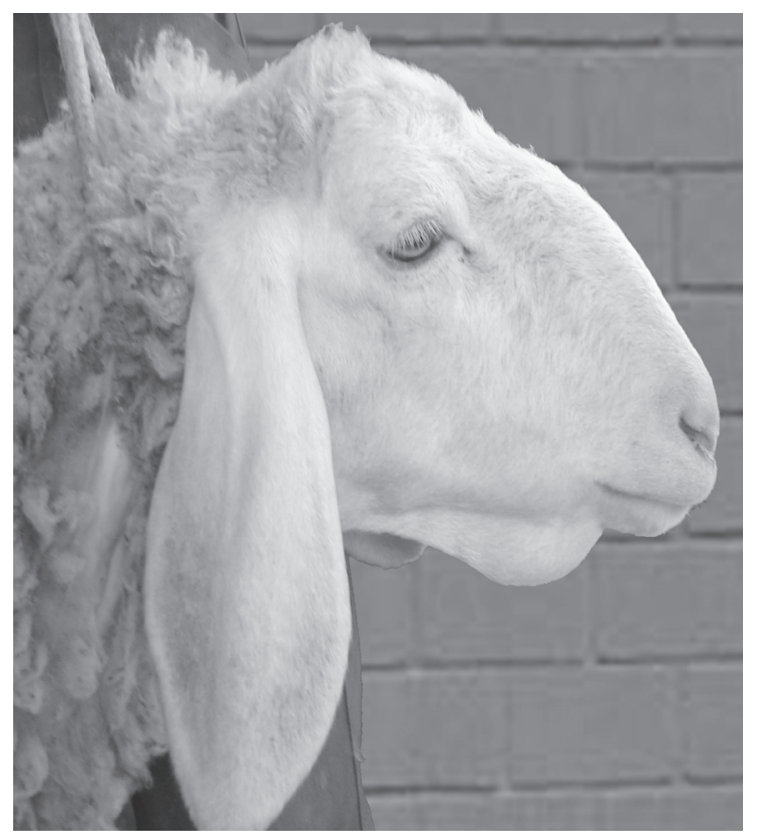

Fig.1. Ovino apresentando aumento de volume de consistência pétrea, fixo na região inferior da mandíbula.

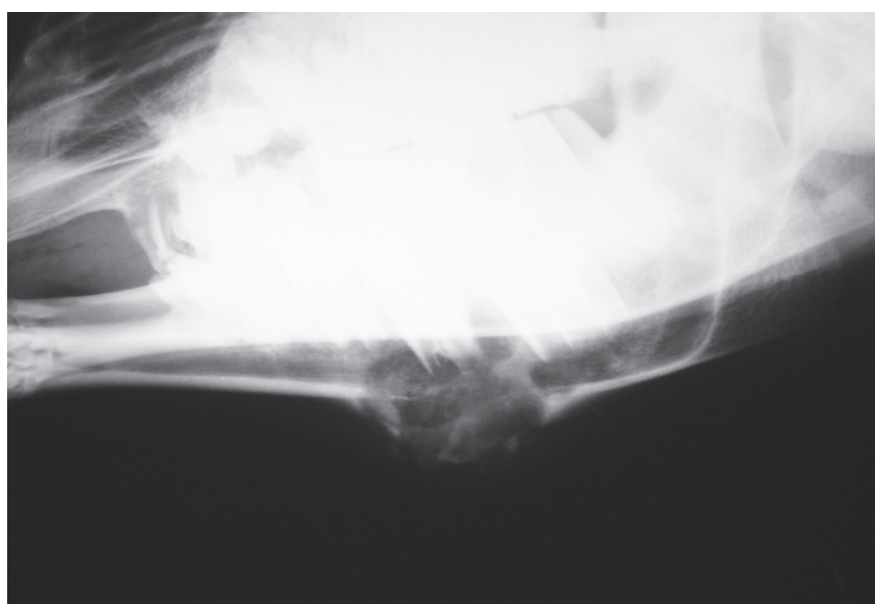

Fig.2. A radiografia revela proliferação óssea com várias formações císticas, lise, rarefação e remodelamento ósseo. 


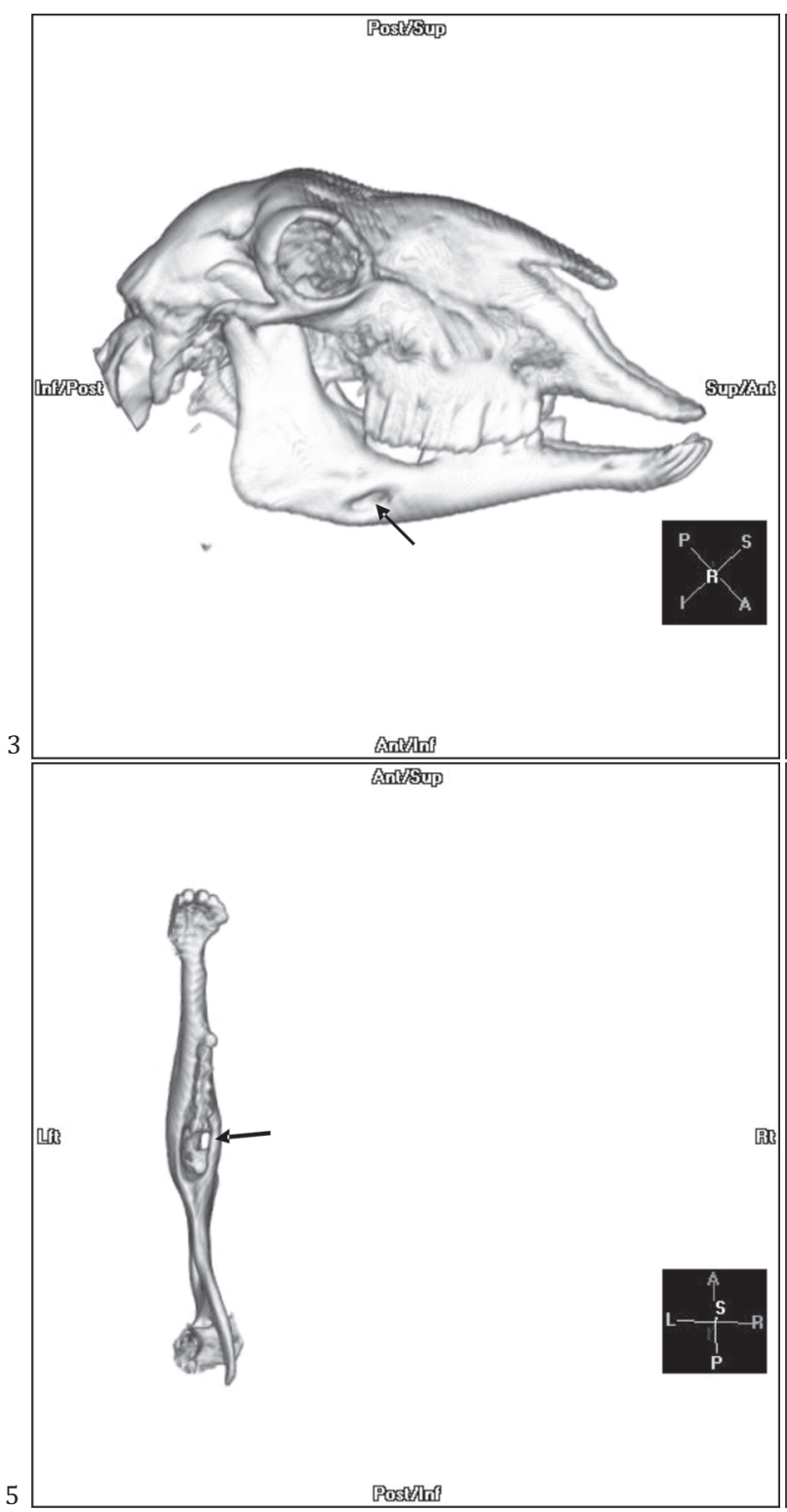

Fig.3. Vista lateral do ramo mandibular direito no crânio de ovino com presença de fístula óssea (seta).

Fig.5. Vista dorsal do ramo mandibular direito de ovino com presença de fístula óssea (seta).

gãos. No exame de cultivo microbiológico do conteúdo do nódulo mandibular, coletado durante a necropsia desse animal e em outros cinco animais por punção aspirativa, houve crescimento bacteriano de Pseudomonas aeruginosa.

Ao exame histopatológico (Fig.7) observou-se a desvitalização e necrose do tecido ósseo, juntamente com a presença de tecido conjuntivo denso. Não foi observada a presença de processo inflamatório. Esses achados podem ser justificados pela cronicidade da lesão, uma vez que esse fragmento ósseo foi obtido meses após o seu aparecimento.

Ao exame radiográfico da região mandibular de 19 animais detectou-se proliferação óssea com várias formações císticas, lise, rarefação intensa e remodelamento ósseo.

Ao exame tomográfico do crânio de um dos animais cronicamente afetado observou-se cavitações no terço médio do
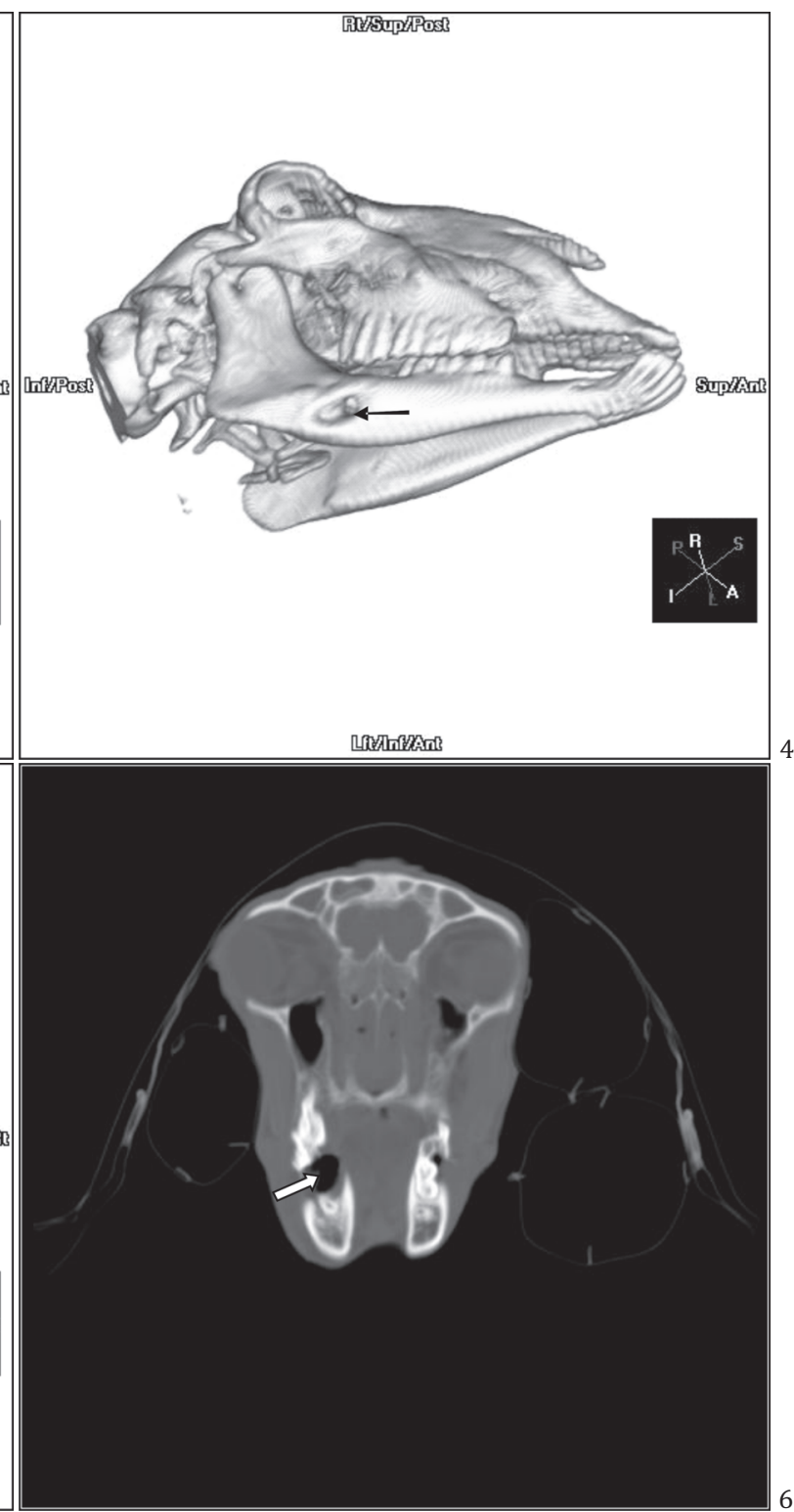

Fig.4. Vista ventral do ramo mandibular direito no crânio de ovino com presença de fístula óssea (seta).

Fig.6. Imagem tomográfica do crânio de um ovino com cavitação no ramo mandibular direito (seta) decorrente de abscesso ósseo.

ramo mandibular direito e formação de uma fístula (Fig.35), devido a um abscesso ósseo. $\mathrm{Na}$ reconstrução tridimensional da imagem tomográfica podemos observar o trajeto fistuloso (Fig.3-5).

0 tratamento utilizado foi baseado na aplicação de iodeto de sódio a $10 \%$ ( $1 \mathrm{~g} / 12 \mathrm{~kg}$ de peso corporal, por 3 dias consecutivos), por via intramuscular, associado à antibioticoterapia segundo antibiograma com enrofloxacina $7,5 \mathrm{mg} / \mathrm{kg}$ de peso vivo durante 20 dias, este tratamento foi instituído devido a suspeita clínica de um granuloma actinomicóide, porém o tratamento não teve eficácia nos animais gravemente acometidos.

A utilização incorreta de pistolas dosificadoras para o tratamento anti-helmíntico em ovinos pode provocar lesões traumáticas perfurantes na cavidade oral. Principalmente no in- 


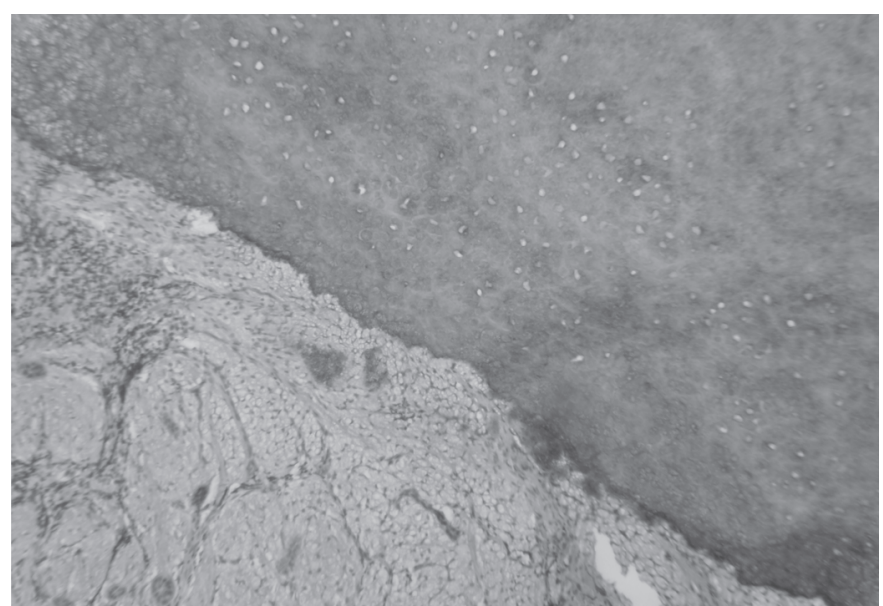

Fig.7. Tecido ósseo desvitalizado (necrose) e tecido conjuntivo denso, de ovino com abscesso por Pseudomonas aeruginosa. HE, 100x.

verno, algumas pastagens como o cultivar Tanzânia, por ser cespitoso, formam estruturas rígidas pontiagudas que também podem provocar esse tipo de lesão (López 1998, Sant'Ana et al. 2007).

Radostits et al. (2002) alertam para o fato de que lesões traumáticas na cavidade oral de ruminantes podem trazer sérias consequências, pois agentes oportunistas, principalmente bacterianos, podem aproveitar essa porta de entrada e migrar para outros tecidos e sistemas.

Neste estudo sugere-se que estas lesões provocadas pelo talo do capim e por ferimentos provocados pela pistola dosificadora sejam os locais de entrada de Pseudomonas aeruginosa e por consequência da formação dos abscessos no tecido ósseo da mandíbula.

Pseudomonas aeruginosa é um microrganismo Gram-negativo, oportunista, extremamente versátil, que pode ser encontrado em diversos ambientes, principalmente no solo e água, ou ainda associado a plantas e animais. Pode causar infecções, principalmente em trato genito-urinário, digestivo, respiratório, lesões dermatológicas e no tecido ósseo, além de estar envolvido em processos supurativos em ruminantes (Todar 2008).

Os principais diagnósticos diferenciais neste caso eram: formação de abscessos por lesões na cavidade oral e região da orofaringe, actinobacilose, tuberculose e granuloma actinomicóide que pode ser causado por diversos agentes como Actinomyces bovis, Actinobacillus lignieresii, Nocardia spp., Staphylococcus aureus, Streptococcus spp., Pseudomonas aeruginosa e Arcanobacterium pyogenes.
As lesões observadas eram fixas, acometiam o tecido ósseo e não apresentavam rápida recuperação após serem drenadas, curetadas e tratadas, como seria esperado para a evolução de abscessos. Excluiu-se também a actinobacilose, pois as lesões se localizam na língua e lábios; e tuberculose, na qual as lesões se localizam nos linfonodos e pulmões (nem sempre) (Andrade et al. 1991, Mondadori et al. 1994). Os achados do exame físico, radiográfico e necroscópico não eram compatíveis com essas enfermidades.

Portanto, nos casos das ovelhas apresentadas neste trabalho, os exames clínico, radiográfico, tomográfico, microbiológico e necroscópico permitiram o diagnóstico etiológico de abscesso mandibular por Pseudomonas aeruginosa.

Agradecimentos.- Ao técnico de nível superior Heraldo André Catalan Rosa, do Serviço de Diagnóstico por Imagem, Faculdade de Medicina Veterinária e Zootecnia da Unesp, Campus de Botucatu, SP.

\section{REFERÊNCIAS}

Andrade G.B., Riet-Correa F. \& Mielke P.V. 1991. Estudo histológico e isolamento de micobactérias de lesões similares à tuberculose em bovinos no Rio Grande do Sul. Pesq. Vet. Bras. 11(4):81-86.

Benito-Peña A., Peris B., Aduriz G., Martinez J. \& Corpa J.M. 2010. Purulent nasomaxillary and mandibular osteomyelitis in sheep caused by Pseudomonas aeruginosa. Vet. Rec. 166:115-116.

Curcio B.R., Gomes F.R., Melo D.M., Raffi M.B., Riet-Correa F. \& Ladeira S.R.L. 2002. Isolamento de Arcanobacterium pyogenes de granuloma actinomicóide em bovino. Ciência Rural 32(5):885-889.

Feitosa F.L.F. 2008. Semiologia Veterinária: a arte do diagnóstico. $2^{\underline{a}}$ ed. São Roca, São Paulo, p.65-86.

López A. 1998. Sistema respiratório, p.132-193. In: Carlton W.W. \& McGavin M.D. (Eds), Patologia Veterinária Especial. Thomson. $2^{\text {a }}$ ed. Artmed, Porto Alegre.

Mondadori A.J., Riet-Correa F. \& Carter G.R. 1994. Actinobacilose em bovinos no Rio Grande do Sul. Ciência Rural 24(3):571-577.

Palmer N.C. 1993. Bone and joints, p.1-181. In: Jubb K.V.F., Kennedy P.C. \& Palmer N.C. (Eds), Pathology of Domestic Animals. $4^{\underline{a}}$ ed. Academic Press, Orlando.

Radostits O.M., Gay C.C., Blood D.C. \& Hinchcliff K.W. 2002. Clínica Veterinária: um tratado de doenças dos bovinos, ovinos, suínos, caprinos e eqüinos. 9a ed. Guanabara Koogan, Rio de Janeiro, p.840-843.

Sant'ana F.J.F., Garcia E.C., Rabelo R.E., Costa Y.L., Schild A.L. \& Riet-Correa F. 2007. Lesões orofaríngeas e neurológicas em ovinos associadas ao uso de pistolas dosificadoras. Pesq. Vet. Bras. 27(7):282-286.

Todar K. 2008. Pseudomonas aeruginosa. Todar's Online Textbook of Bacteriology, junho, 2009. Disponível <http://www.textbookofbacteriology.net/ pseudomonas.html> Acesso em 12 jun. 2009.

Weiss R.D.N. \& Santos M.N. 1992. Determinação da etiologia de granulomas actinomicóides em bovinos no Rio Grande do Sul através da histoquímica. Pesq. Vet. Bras. 12(4):71-76. 